\title{
Hill of Value financial metrics used to optimise the Carrapateena project
}

\author{
RJ Hocking OZ Minerals, Australia
}

AJ Mooney OZ Minerals, Australia

L McFadyen OZ Minerals, Australia

\begin{abstract}
Carrapateena is a sub level cave operation located in South Australia. The sub level cave is scheduled to reach a production rate of $4.25 \mathrm{Mtpa}$ by the end of 2020. Hill of Value analysis identified that replacing the lower half of the current sub-level cave with a block cave and expanding the expected annual throughput rate from 4.7-5.0 Mtpa (currently planned from 2023) to $12 \mathrm{Mtpa}$, has the potential to create significantly more value than the sub-level cave alone. Stage 1 of the Block Cave Expansion Feasibility Study is now underway with completion expected late 2021. The sub level cave to block cave transition presented a unique scenario for optimisation during the scoping study. This paper focuses on optimising the financial performance of the lower block cave using Hill of Value optimisation techniques, taking into account the depletion of the sub level cave at the same time. Various production rates, capital and operating costs, as well as transition timing options were considered within the Hill of Value model. A comparison was performed of how prioritising particular financial investment metrics (Net Present Value (NPV), Internal Rate of Return (IRR), Present Value Ratio (PVR) or Return on Invested Capital (ROIC)), influenced the optimised mine design, rate and schedule. Hill of Value offers the opportunity to optimise the design of the mine at the start of the project, dependent on the goals of the study and broader organisation. This paper shows a thorough method of completing this analysis, while considering the various financial metrics, thereby enabling future studies to consider implications to the mine plan as more information is discovered during the study.
\end{abstract}

\section{Introduction}

\section{$1.1 \quad$ OZ Minerals}

OZ Minerals is a copper-focused, global, modern mining company based in South Australia. Its growth strategy is focused on creating value for all its stakeholders. OZ Minerals owns and operates the Prominent Hill and Carrapateena mines in South Australia, the Antas mine in the Pará state of Brazil, is constructing the nearby Pedra Branca underground mine, and has earn-in agreements with experienced exploration companies to create a pipeline of future potential growth opportunities.

The Carrapateena copper-gold mine is located approximately $160 \mathrm{~km}$ north of Port Augusta, in South Australia's highly prospective Gawler Craton (Figure 1). The project is located on Pernatty Station and its supporting infrastructure is located within Oakden Hills Station. The Kokatha people are the traditional owners of the land.

The base case for the Carrapateena mine is a sub level cave from $500 \mathrm{~m}$ to 1,500 $\mathrm{m}$ below surface, with crushers at the top, middle and bottom of the mine as shown in Figure 2. This figure shows the mine layout of the base case plan for the sub level cave. The decline was started in 2016, with the first production level reached in 2019. 


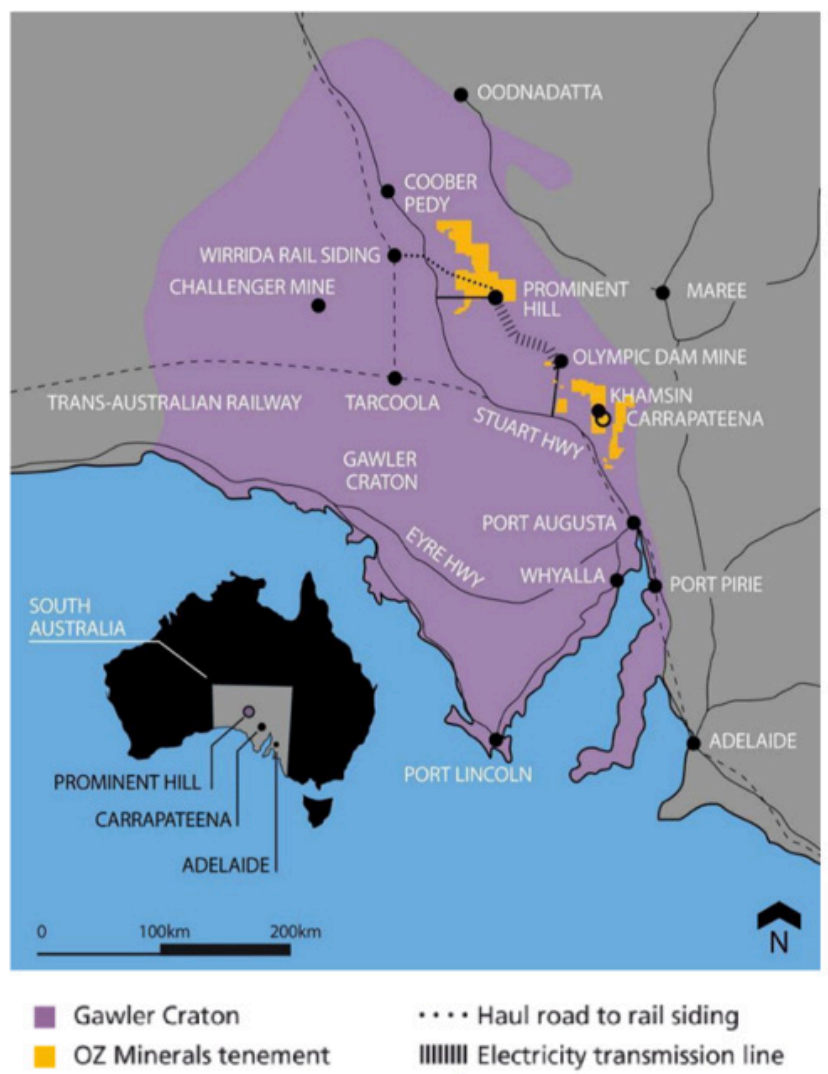

Figure 1 Carrapateena location map

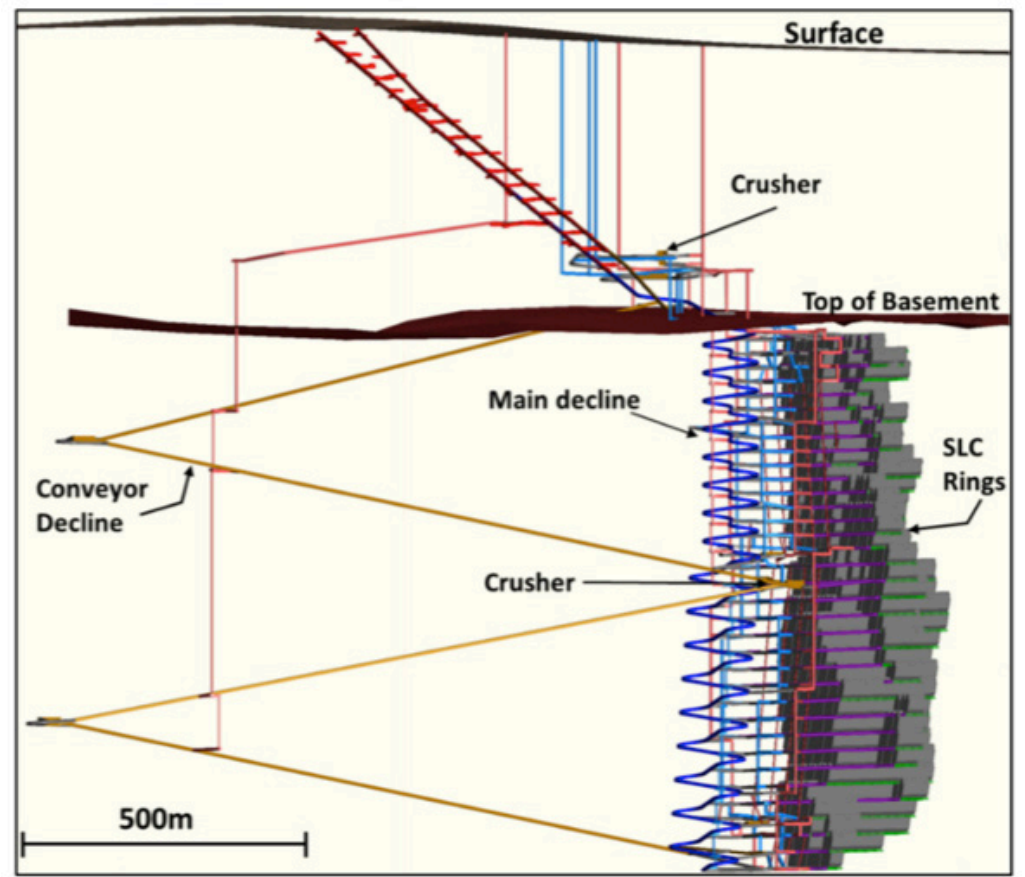

Figure 2 Layout of Carrapateena sub level cave (from Hocking et al. 2018)

In 2018, a study began to evaluate the potential expansion of the sub level cave (top down method) and replace the bottom half of the mining method with a block cave mining method. This paper focuses on the way the model was designed to improve the optimisation using the Hill of Value method originally outlined by Hall, 2012. By examining the key levers of a block cave concurrently (the footprint size, elevation and mining rate), the best case could be put forward to maximise value for the shareholder and other stakeholders, in addition to understanding the value of additional capital. 
Often late in the completion of a study, the team will be told to optimise to a number of financial metrics which are contradictory, such as IRR, NPV and ROIC. These metrics do not lead to the same mine plan, resulting in trade-offs between each other.

\section{$1.2 \quad$ Hill of Value}

Hill of Value is a method that looks at variable cut off values, which vary with rate. Hall (2003) redefined the definition of cut-off grade, showing that the highest NPV is not created through maximising the reserve of the deposit. Hall (2012) outlined a brief method for the calculation of the optimal cut off based on Hill of Value, which has been expanded upon in this paper for the specific example of a Block Cave transitioning to a sub level cave. Initially, for a given production rate and capital cost, the optimal cut-off grade can be determined for both discounted and undiscounted cases, with the peak of the undiscounted case at the marginal cut off for the mine. The highest discounted value has been shown by Hall (2012) to be at a higher cut off, resulting in a smaller, higher grade mine as shown in Figure 3(a).

In the case of an expansion, capital can increase gradually through production rate, with additional larger increases due to hard constraints at certain cut offs (Figure 3(b)). The model discussed in this paper flexes these values and the cut-off value to determine all possible scenarios and plot them over a range of financial metrics. Essentially for any given production rate, there is an optimum cut-off grade that is based on the economics of the project, which also includes the capital and operating cost. Hall (2012) shows that the production rate can change as the debottlenecking capital is added to the project (Figure 4), producing a three-dimensional plot of production rate and cut-off grade with a financial metric (usually NPV) on the Z-axis. A Hill of Value looks at optimising the cut-off grade and production rate at the same time, based on the current understanding of the project. Others, such as Vera et al. (2019) have also used this approach.

A systematic approach is needed to determine the optimal cut-off value of a deposit, and the Hill of Value methodology is an effective method to calculate the level, cut off and mining rate of a block cave mine.
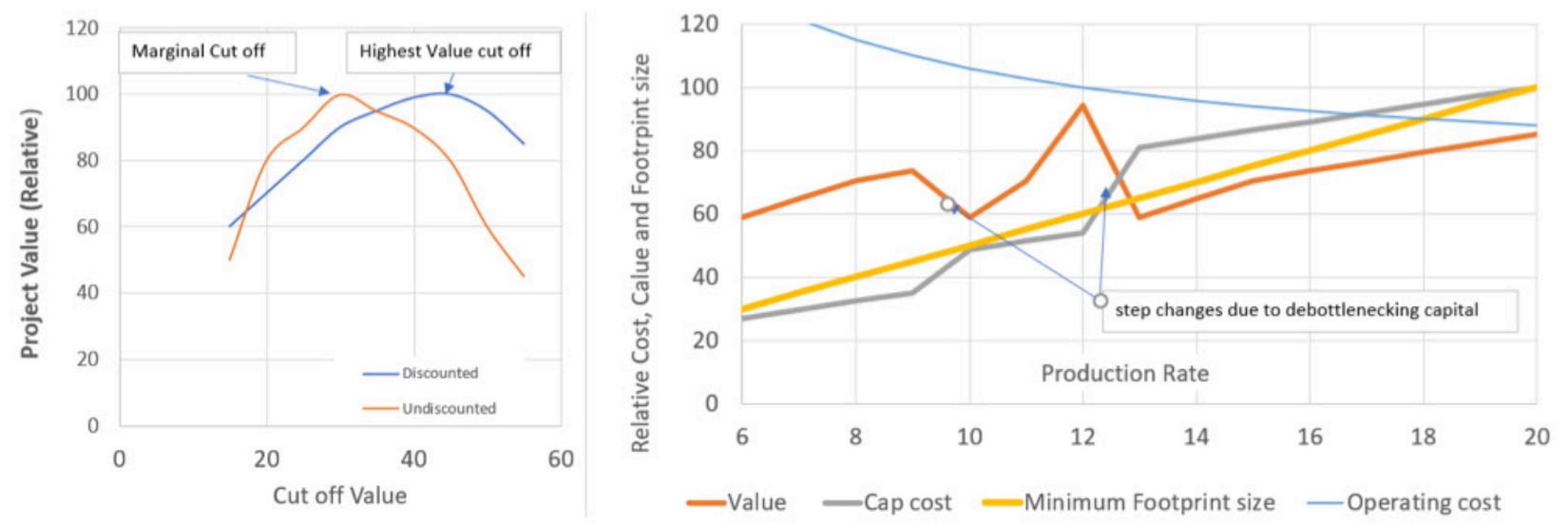

Figure 3 Example of Value optimisation with debottlenecking capital for a mine plan for different cut offs and rates (after Hall 2012) 


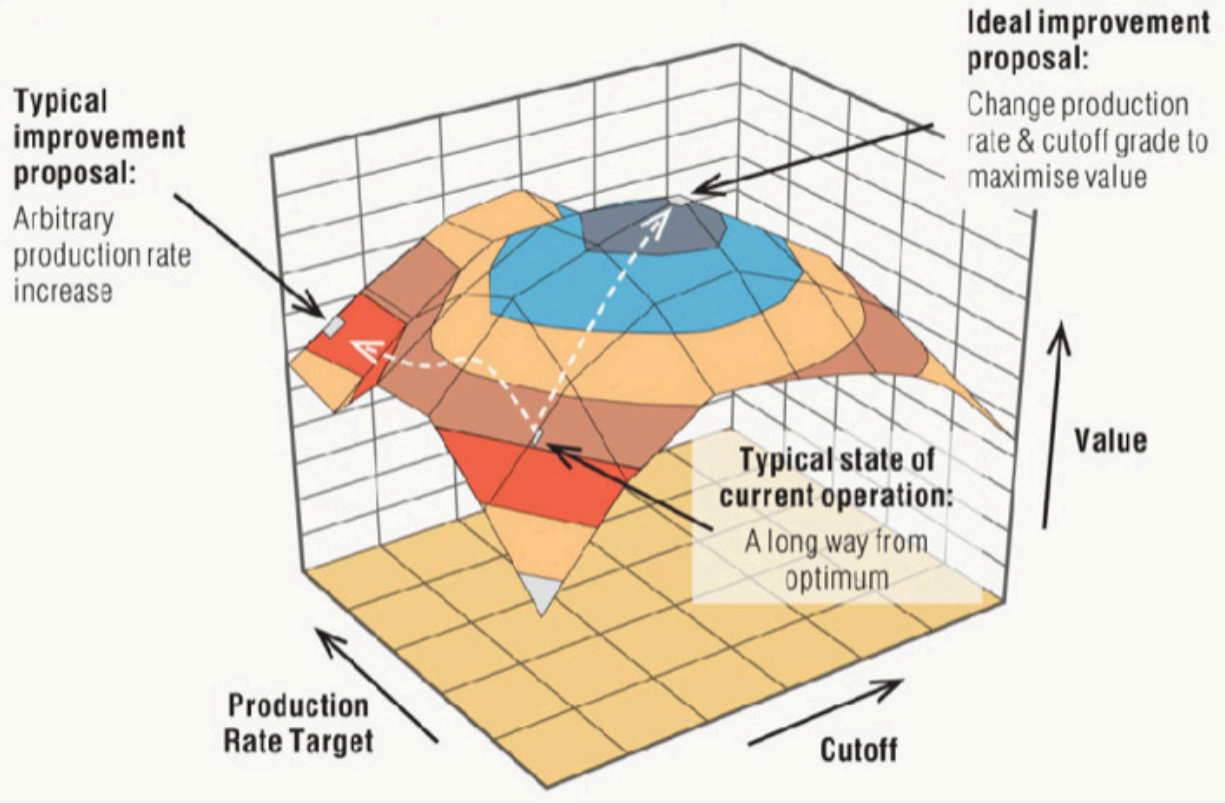

Figure 4 Hill of Value mine optimisation technique from (Hall \& Hall 2015)

\subsection{Carrapateena expansion opportunity overview}

In 2017, the OZ Minerals Board approved the development of Carrapateena as a sub level cave at a rate of 4.25 Mtpa (OZ Minerals 2017). Subsequent to this, a scoping study was released where an alternative mining scenario of a block cave underneath the current sub level cave was considered. The aim was to produce a robust financial metric suitable for progression of the mine to a mining rate of 12 Mtpa. This strategic decision was based on detailed analysis using the Hill of Value mining method. Like all orebodies, Carrapateena has unique challenges, such as availability of water, power and the limitations of the already planned underground materials handling system.

Unique to this optimisation problem, was the depletion of the sub level cave (a top to bottom method), meaning that a delay in a decision could result in a reduction in the economic return of the investment in a block cave. Preliminary mine design identified that there was a decision point at approximately the 4,200 Reduced Level (RL), where the decline needed to be re-routed to satisfy standoffs for the block cave if it were to be mined (Figure 5).

A model based on the Hill of Value methodology was developed based on:

- The depletion of the sub level cave level by level, based on the timing of the block cave production becoming higher than 4.25 Mtpa;

- Capital assumptions;

- Variable starting levels (depth) of the block cave;

- Variable footprint size of the block cave; and

- Variable mining rates from the block cave as shown in Figure 5. 


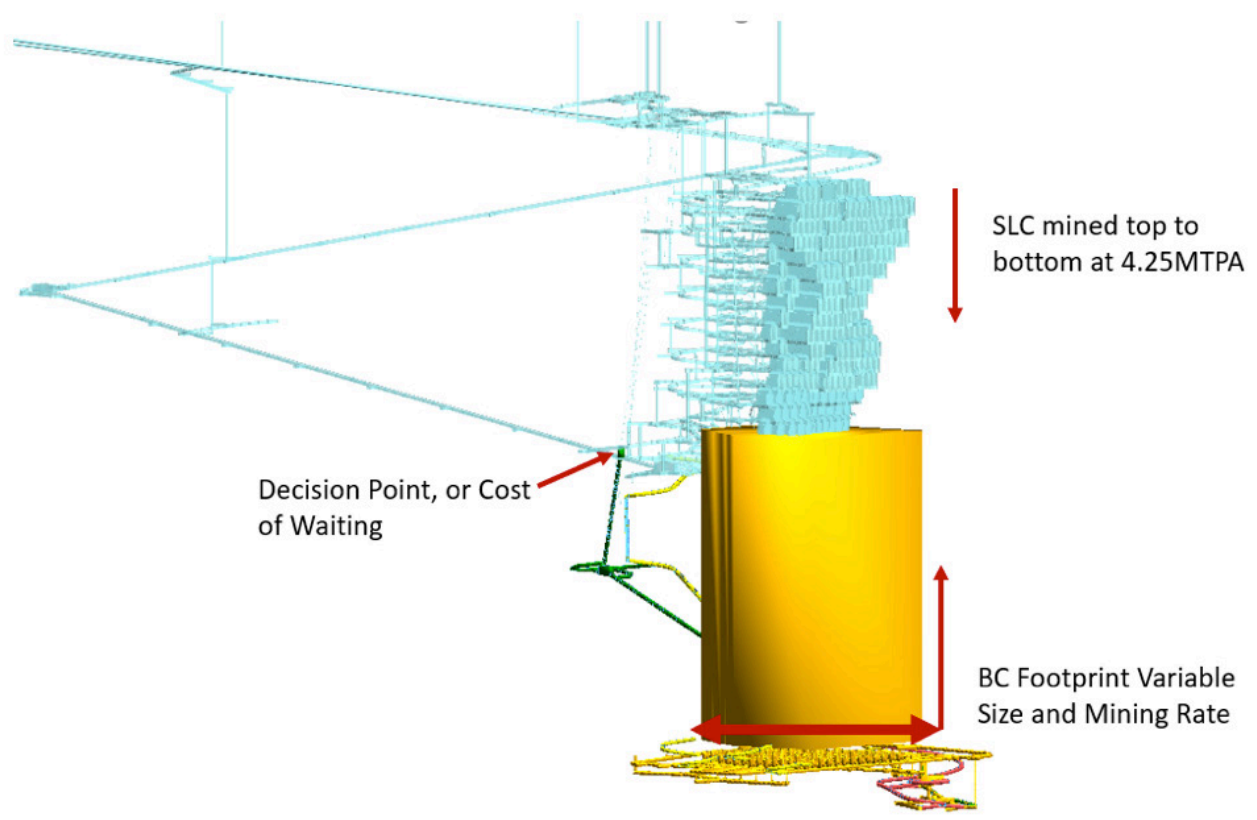

\section{Figure 5 Decision point for Carrapateena}

\section{$1.4 \quad$ Model functional overview}

The block model was aggregated. The Hill of Value model runs on multiple elevations, and calculates the value of each $X, Y$ block based on the total value for the given elevation. The sub level cave material that has been depleted is given background values. The value (in this case NPV) can be calculated $\left(\$ / \mathrm{m}^{2}\right)$ and a cashflow can be calculated by the NSR less the operating cost for a mixed block model, based on Laubscher mixing (Laubscher 1994). This methodology is similar to Personal Computer Block Cave (PCBC) footprint finder (Diering et al. 2010) with the exception of the SLC material depletion. For every given footprint location, a different size footprint can be tested based on changing the cut-off value, with the higher the cut-off value, the smaller the footprint, the shorter the mine life, but the higher the grade. The footprint can then be smoothed using a series of algorithms to make it more realistic if needed, as shown in Figure 6. The mixed footprint can then be mined bottom up (slice by slice) to mimic the assumptions of even drawdown, which is a good assumption for scoping or pre-feasibility studies of a block cave. The mined material is then mined sequentially bottom to top with the calculated head grades, recovery assumptions, as well as operating, royalty and taxes. A financial model can be created that models all these scenarios quickly.
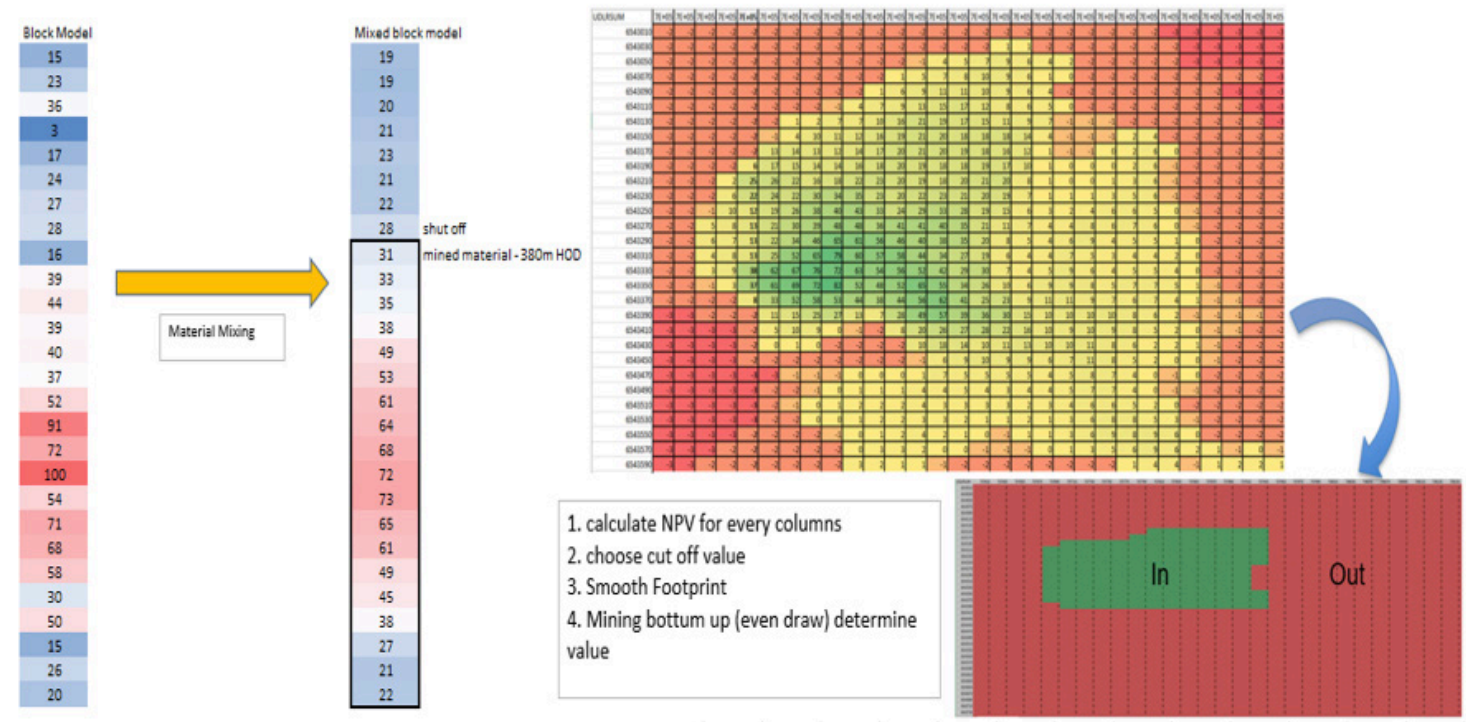

Figure 6 Cut off - mixing and footprint smoothing, mixing is done within the block model based on Laubscher methodology 


\section{$1.5 \quad$ Financial metrics}

Mineral economics is the discipline that investigates the understanding of economic outcomes and issues associated with the production and use of mineral commodities. While its origins can be traced back at least 200 years to the writings of David Ricardo and other early classical economists, it emerged as a separate field only after World War II and then primarily in the United States. While geologists, mining engineers, and others with technical backgrounds were largely responsible for creating the first standalone mineral-economic-valuation models, ultimately, trained economists took over to create superior methods for understanding the true value of a mining opportunity.

Uncertainty is an important feature of many investments, but it is especially important for mineral properties. Mineral properties often entail large investments and fixed commitments. Executives and Boards in the mining industry often view price and technical uncertainty as undesirable, due to the possibility that the price of the mined commodity will fall, or technical challenges will require design reconfigurations that prevent the company from recovering its investment and fixed costs. It is also important to be aware that what might be most valuable for the project is not always the most valuable outcome for the country in which the mining rights reside. The relationship between mining companies and governments (with particular attention on taxes and other ways of sharing the benefits from mining) is another important issue that needs close attention when valuing a mining project, as a number of countries have introduced codes governing the valuation of mineral assets and securities.

The most common approach to valuing development mining projects is discounted cash flow (DCF) analysis to determine the NPV of a stream of estimated future cash flows. The DCF method can also be used for marginal development properties, but its usefulness is doubtful because low or negative values may be derived that do not necessarily reflect the market value. The DCF method is a well-established and standard method used in the mining industry to value development properties. Such properties are commonly bought and sold on the basis of NPV derived from DCF analysis. DCF analysis requires that the property is sufficiently advanced to ensure that reliable and up-to-date information is available in the following areas:

- Reasonably assured mineable reserves (proven and probable);

- Mining plan, rate and schedule;

- Metallurgical test or operating results;

- Process recovery and design;

- Capital cost estimates including mine, process plant, surface facilities and infrastructure, environmental compliance, decommissioning and reclamation, working capital, etc.; and

- Operating cost estimates including mining, processing, administration and management, transportation, infrastructure, environmental compliance, sales and royalties.

The main advantage of the DCF method is that it is well-established, reasonably well understood by nonfinance people and a widely accepted method of valuing advanced mineral properties and operating mines. However, there are two main disadvantages to the method:

- It is commonly applied without due regard for the quality and reliability of the input factors, particularly technical parameters such as mineral reserve tonnage and grade, estimated capital and operating costs, metallurgical recovery, etc.

- It may undervalue mineral properties in times of low commodity prices, or projects with a longterm production profile.

\subsection{Challenges with valuations}

One of the important concepts of fair market value critical to mineral properties is, the effective date of valuation. This is because mineral property values vary over time, depending on events on neighbouring 
properties, market interest, commodity prices, etc The effective date for an expropriation, insurance claim or litigation valuation may be a very contentious issue. This is because the mineral property owner may perceive that the property will be more valuable in the future, when market conditions improve, and that the expropriation or legal issue forces the valuation in poor market conditions.

The discount rate refers to the interest rate used to determine the present value of future cash flows and is the minimum required rate of return, or the hurdle rate. The primary issue with the application of a discount rate is that only one discount rate is commonly used at a point in time to value all future cash flows, when in fact interest rates and risk profiles are constantly changing, sometimes in a dramatic way. When using the weighted average cost of capital (WACC) as a discount rate, the calculation centres around the use of a company's beta. The historical volatility of returns is not necessarily a good measure of how risky a business will be in the future.

\subsubsection{Net Present Value (NPV)}

NPV is the value of all future cash flows (positive and negative) over the entire life of an investment, discounted to the present. It is an all-encompassing metric, as it considers all revenues, expenses, and capital costs associated with an investment (Corporate financial Institute website 2020).

$$
\mathrm{NPV}_{\mathrm{XYZ}}=\frac{\mathrm{Z}_{1}}{1+\mathrm{r}}+\frac{\mathrm{Z}_{2}}{(1+\mathrm{r})^{2}}-\mathrm{X}_{0}
$$

Where:

$$
\begin{aligned}
& \mathrm{Z}_{1}=\text { cashflow in time period } 1 \\
& \mathrm{Z}_{2}=\text { cashflow in time period } 2 \\
& \mathrm{R}=\text { discount rate } \\
& \mathrm{X}_{0}=\text { cash outflow }
\end{aligned}
$$

\subsubsection{Internal Rate of Return (IRR)}

The IRR is the discount rate that makes the NPV of a project zero. In other words, it is the expected compound annual rate of return that will be earned on a project or investment as outlined in Equation 2, defined by Corporate Financial Institute, 2020.

$$
\mathrm{NPV}=\sum_{\mathrm{n}=0}^{\mathrm{N}} \frac{\mathrm{CF}_{\mathrm{n}}}{(1+\mathrm{IRR})^{\mathrm{n}}}=0
$$

Where:

$$
\begin{aligned}
& \mathrm{CF}_{0}=\text { Initial Investment /Outlay } \\
& \mathrm{CD} 1, \mathrm{CF} 2, \mathrm{CF} 3 \ldots \mathrm{CFn}=\text { Cashflows } \\
& \mathrm{N}=\text { each period } \\
& \mathrm{n}=\text { Holding Period } \\
& \mathrm{NPV}=\text { Net Present Value } \\
& \mathrm{IRR}=\text { Internal Rate of Return }
\end{aligned}
$$

\subsubsection{Present Value Ratio (PVR)}

PVR is the ratio of NPV to the present value of the invested capital. For caving projects, this compares discounted values and discounted capital costs. PVR is used as a project ranking tool to allocate capital between competing projects. Discounted capital expenditure is important when evaluating PVR for caving mines, as the capital is spread over more than a decade in some cases. Stewart and Butcher (2016) discuss the significance of this ratio in large block cave projects. They examined a number of different scenarios (Figure 7) and showed that this metric was an effective one to use when ranking projects, such as block 
caves with long payback periods. This concept is particularly important when projects are compared when there is limited capital to spend.

In larger companies that have competing projects (caving and non-caving), the maximum PVR option selected may provide a better overall NPV outcome for the entity than the maximum NPV option (Stewart \& Butcher 2016).

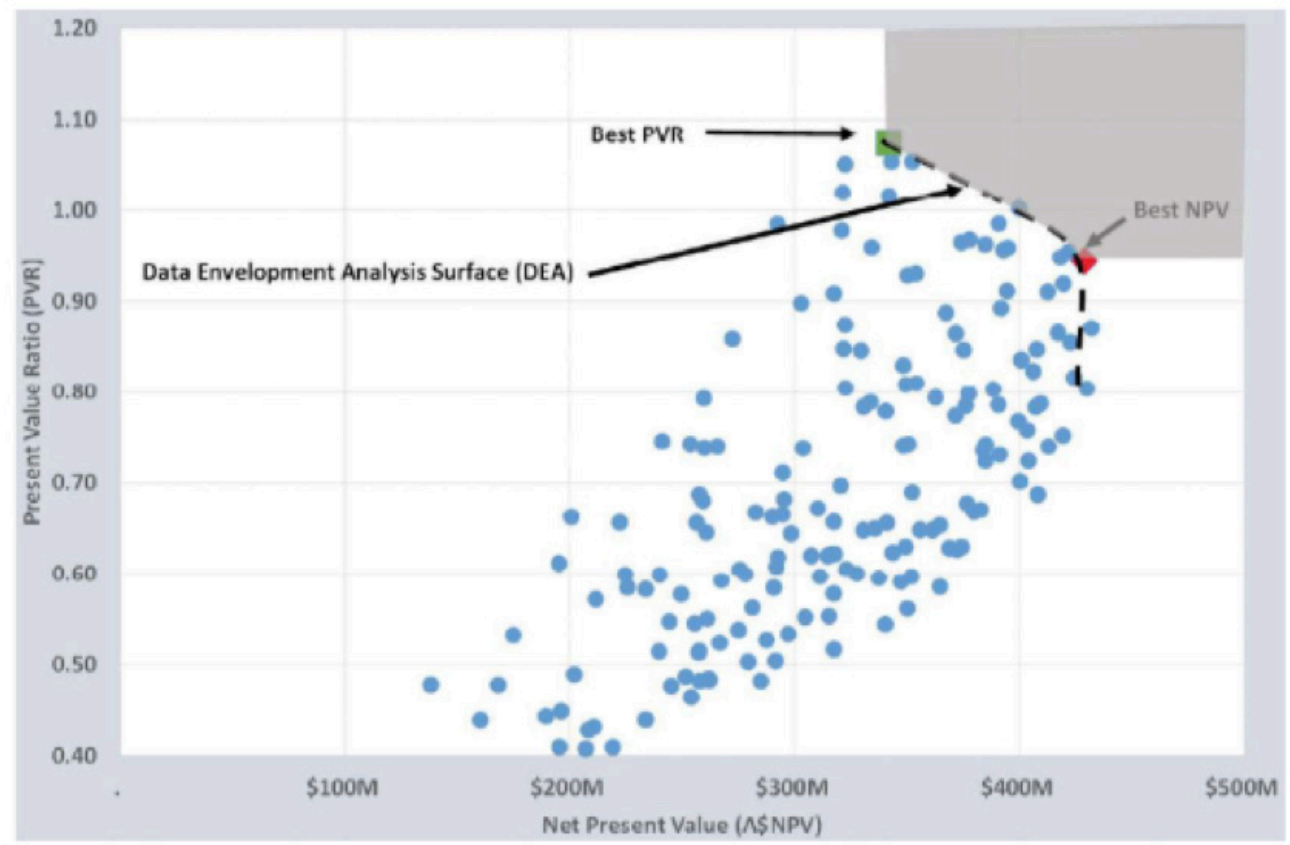

Figure 7 Net Present Value (NPV) versus Present Value Ratio (PVR) data envelope analysis (Stewart \& Butcher 2016)

\subsubsection{Return on Invested Capital (RIOC)}

ROIC is a profitability or performance ratio that aims to measure the percentage return that investors in a company are earning from their invested capital (Corporate finance Institute 2020) and is shown in Equation 3. The ratio shows how efficiently a company is using the investors' funds to generate income. Benchmarking companies use ROIC ratio to compute the value of other companies. A company can evaluate its growth by looking at its ROIC ratio. Any firm earning excess returns on investments totalling more than the cost of acquiring the capital is a value creator and therefore, usually trades at a premium. Excess returns may be reinvested, thus securing future growth for the company. An investment whose returns are equal to or less than the cost of capital is a value destroyer.

$$
\text { Return on Invested Capital }\left(\text { ROIC) }=\frac{\text { Net Operating Profit After Tax }}{\text { Invested Capital }}\right.
$$

\section{$2 \quad$ Financial and scheduling assumptions}

The sub level cave to block cave Hill of Value model is based on the assumptions below.

\subsection{Net Smelter Return (NSR) model}

The NSR model is based on $70 \%$ of the in-situ value of the ore block, based on the current reserve price of the ore. This has been shown to be within 1\% of the NSR calculation based on concentrate sales and recovery assumptions (Masters \& Hocking 2019).

\subsection{Capital and operating cost assumptions}

Capital cost assumptions are based on the level at which the block cave is simulated, the size of the footprint, and the production rate assumptions, as shown by Table 1. As the footprint gets deeper, the 
cost increases. As the footprint gets bigger, the perimeter drives and the footprint area increases. As production rate increases, the capital above ground increases, such as increase in mill size, ventilation and water supply. A series of capital jumps were identified at $12 \mathrm{Mtpa}$ at Carrapateena, based on changes to the materials handling system and the water supply.

Table 1 Different bins of capital based on $\mathrm{RL}$, rate and footprint size

\begin{tabular}{|c|c|c|}
\hline Capital Based on RL & Footprint Size Capital Assumptions & Rate Based Capital Assumptions \\
\hline Ventilation rises (length) & Footprint area $\left(\$ / \mathrm{m}^{2}\right)$ & Mill size \\
\hline Declines & Perimeter drives & Mining fleet \\
\hline Conveyors & & Ventilation quantity (based on rate) \\
\hline Transfer stations & & MHS size \\
\hline & & Water supply \\
\hline & & Crusher installation \\
\hline & & Vent rises (width) \\
\hline
\end{tabular}

\subsection{Operating assumptions}

Operating cost for the block cave was assumed to vary between $\$ 20$ to 30\$/tonne dependent on mining rate, including capex at a mining rate of $12 \mathrm{Mtpa}$. This was based on a first principles cost model that was built for the scoping study. For the purpose of this analysis, the model was set up so the operating cost was flexed on an assumed ratio between fixed and variable costs as shown in Figure 3(b).

\subsection{Flow assumptions}

For each column, a uniform mixing is assumed based on Laubscher mixing models (Laubscher 2000), based on a $160 \mathrm{~m}$ interaction height.

\subsection{Block cave ramp up}

The block cave ramp-up is based on other benchmarked operations of similar size, complexity and workforce, throughout Australia in the last 10 years.

\subsection{Sub level cave depletion}

The sub level cave is assumed to be mined top down, as per the current mine plan. When the block cave reaches a production rate exceeding the sub level cave, then the $\mathrm{RL}$ of the sub level cave can be calculated based on the timing of the block cave. The material is depleted and assigned a grade of $0.3 \% \mathrm{Cu}$ and 0.2 ppm Au. This assumption is expected to be less than the actual depleted grade, providing an opportunity for refinement in future work, including calibration of the sub level cave model.

\subsection{Tax assumptions}

Accelerated deprecation is used with a simplified model, based on the Australian tax laws.

\subsection{Model calibration}

The Hill of Value model was calibrated to ensure it was within 5\% of the corporate models. These were detailed models for a number of scenarios, which included all costs, treatment and refining charges, and took into account depreciation. Corporate financial models are often tested on 1 to 10 cases in a high level of detail. With the Hill of Value tool running upwards of 20,000 higher level strategic financial models, they were not required to be done to the same level as the official corporate models, but they provided calibrated valuations and identified relative value opportunities. 


\section{$3 \quad$ Results}

For each starting year, mining levels between 3,500 RL and 3,900 RL, production rates of 6 to 25 Mtpa and footprint sizes between $25,000 \mathrm{~m}^{2}$ and $200,000 \mathrm{~m}^{2}$ were tested by setting up a macro to run all the scenarios. For each scenario, the full capital and cashflow profile was calculated, as well as the key metrics from the organisation:

- Net Present Value (NPV)

- Present Value Ratio (PVR)

- Internal Rate of Return (IRR)

- Return of Average Capital Employed (ROIC)

There are many different views on what the most important metric is, so it was important to be clear as to what the trade-offs were for different scenarios.

\subsection{Maximising value based on footprint area, reduced level and financial metrics given a single production rate}

Based on an earlier OZ Minerals Feasibility Study in 2014 of a large block cave (prior to the sub level cave study), a mining rate of $12 \mathrm{Mtpa}$ was favoured, so this was initially chosen as the more ideal production rate. For each footprint area and undercut level shown, the NPV, PVR, IRR and ROIC could be plotted on the same scale as shown in Figure 8. It can be seen that the RL of 3,700 is the top of the peak for NPV and PVR, with footprint areas of between 55,000 $\mathrm{m}^{2}$ and $80,000 \mathrm{~m}^{2}$. When IRR was considered as the key metric, the footprint was substantially smaller, at approximately $40,000 \mathrm{~m}^{2}$, and the footprint elevation was not as sensitive a metric. When ROIC was used as the key metric, the footprint used tended towards the deepest cave with the biggest footprint and largest reserve, which also coincided with the biggest capital cost.
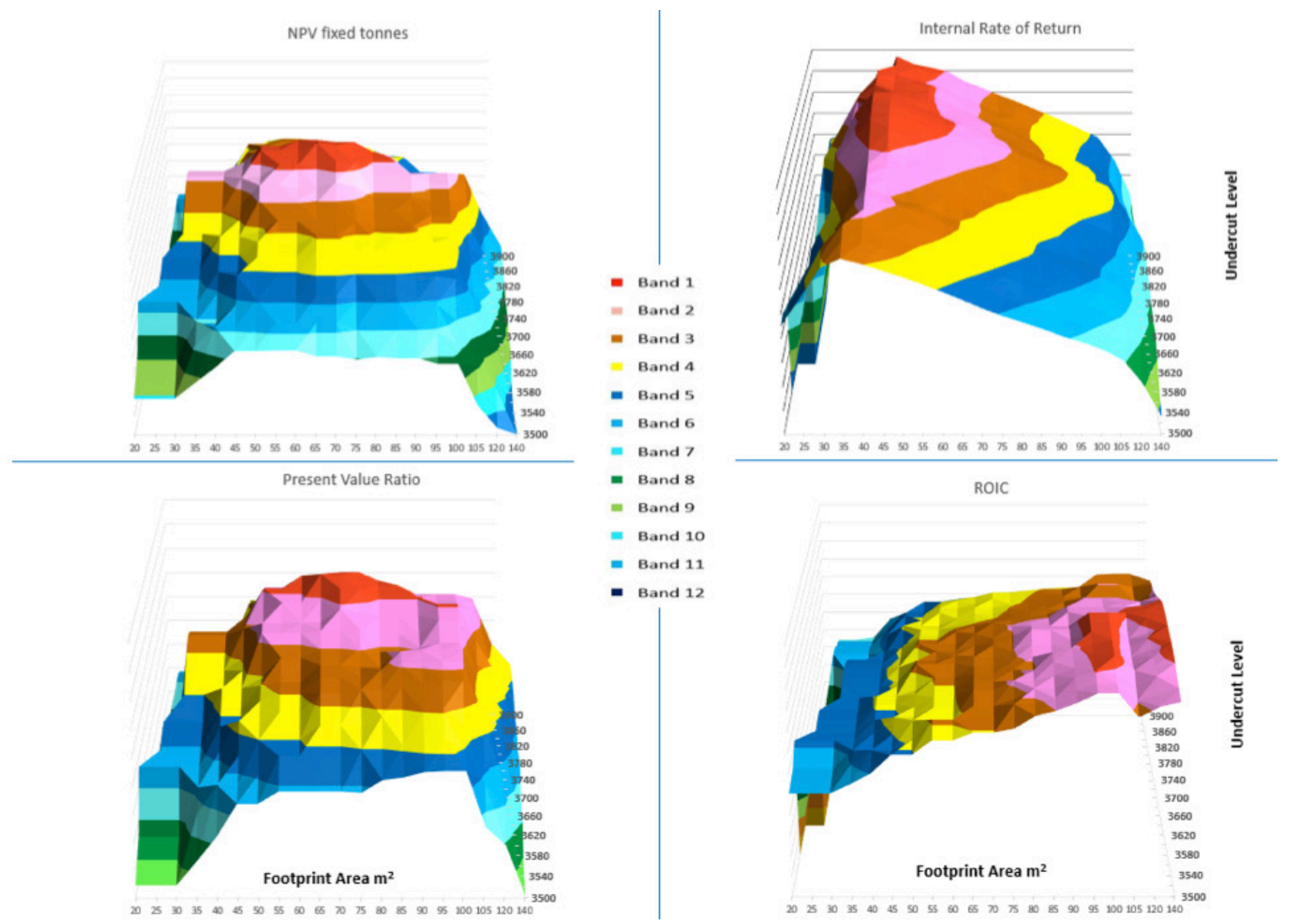

Figure 8 NPV, IRR, PVR and ROIC plotted against footprint area and undercut level 


\subsection{Optimising production rate based on financial metrics}

When mining rate is added as a variable, the highest value (selected footprint) was determined for each selected metric, so the best footprint was selected dependent on what was being optimised. The results for the four different metrics are shown in Figure 9. For NPV, there are two key peaks, one at 12 Mtpa at a footprint of 3,700 Elevation, and another at $25 \mathrm{Mtpa}$. However, this second peak corresponds to a mining rate of $25 \mathrm{Mtpa}$ at a footprint size of $100,000 \mathrm{~m}^{2}$, which would result in a productivity exceeding industry benchmarks. The peak IRR was much clearer at the 3,700 Elevation, and no second peak, as the return on the additional rate capital did not lead to an additional peak. A similar result to IRR was shown for PVR, footprint on the 3,700 Elevation, mining rate of $12 \mathrm{Mtpa}$. The ROIC optimisation showed that the best footprint did not expand the mine at all and has low relative NPV and IRR.

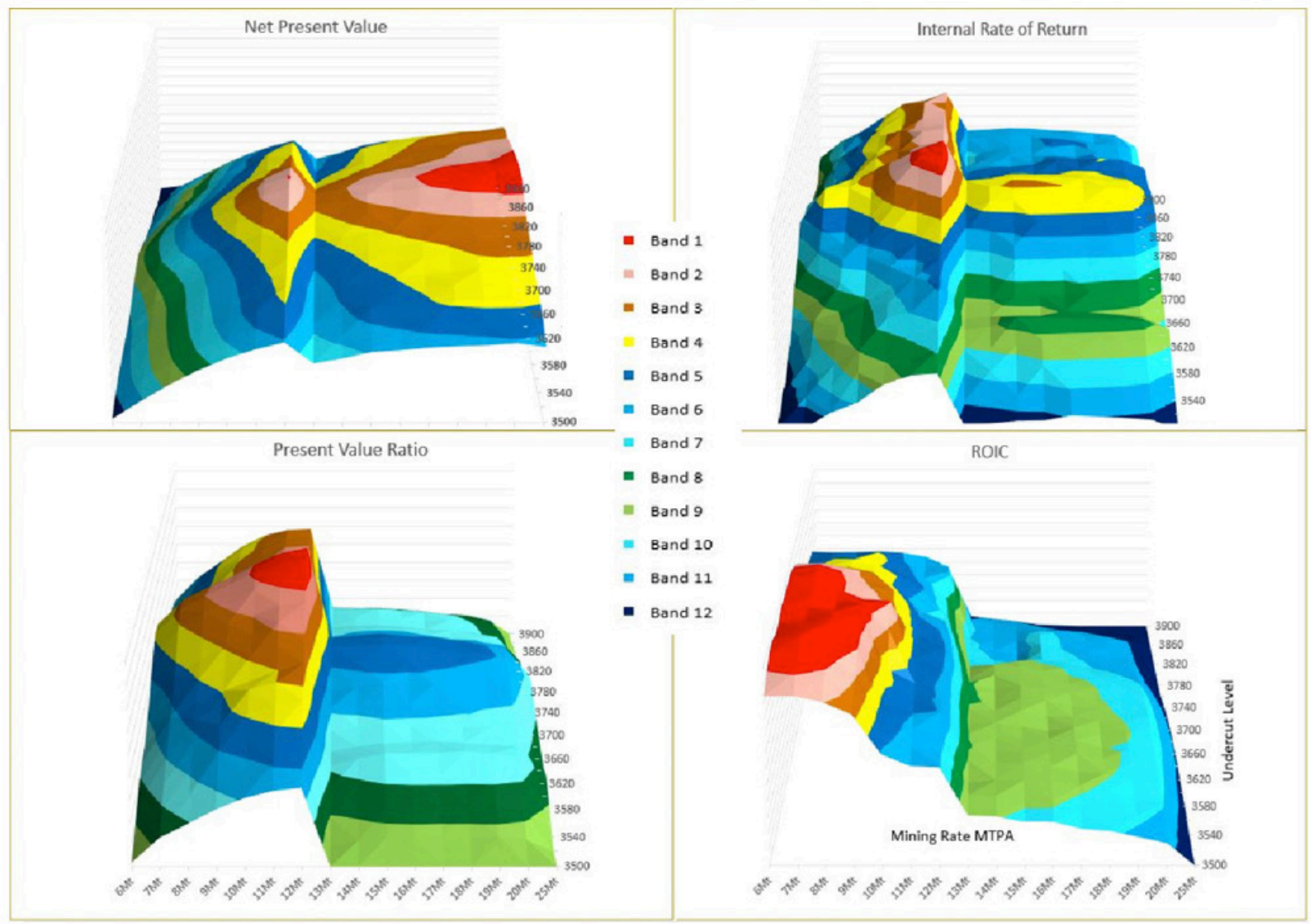

Figure 9 NPV, IRR, PVR and ROIC plotted against production rates

NPV, IRR and PVR all show that the peak is just before investment dictions to duplicate the material handling system (shaft/conveyor) and additional capital requirement. Further rate increase does have suitable payback, due to tonnes/grade/rate profile. Additional footprint size expands into lower grade to meet the production rate, and by doing so dilutes the higher-grade material. The ROIC metric in isolation shows that you would not expand and would utilise what you already have. This represents a lost opportunity based on how it was measured.

To note, while the mining rate was found to be the same as the 2014 feasibility study, the optimised footprint size was smaller than the 100,000 $\mathrm{m}^{2}$ footprint of the 2014 feasibility study. This highlights the impact of adding additional low-grade material and its impact on reducing PVR and NPV, or in other words, the economic benefits of a smaller high-grade footprint.

\subsection{Summary of Hill of Value 'peaks'}

For the purpose of this analysis, the resulting scenario and footprints based on the best NPV, IRR, PVR and ROIC are shown in Table 2. Relative rankings are shown for each metric, comparing the results of optimising a footprint on one financial metric to the other financial metrics. A number of discount rates 
can be chosen for PVR and NPV calculations and produce similar results to each other. When IRR is chosen as the selected metric, Hill's peak is a much smaller footprint, higher up in the orebody. The converse is observed for the use of the ROIC. As it is an undiscounted term, it pushes the footprint to make the most of all the rate-based capital already spent and is not concerned by the payback period. Therefore, it pushes the footprint to be larger and deeper than the other metrics, resulting in a substantially different investment decision.

Table 2 Comparison of optimal points at a fixed rate of $12 \mathrm{Mtpa}$

\begin{tabular}{|c|c|c|c|c|c|c|c|}
\hline $\begin{array}{c}\text { Optimised } \\
\text { Metric }\end{array}$ & NPV & IRR & PVR & ROIC & $\begin{array}{c}\text { Elevation } \\
(\mathbf{m})\end{array}$ & $\begin{array}{c}\text { Footprint } \\
\left.\text { Size } \mathbf{( m}^{2}\right)\end{array}$ & $\begin{array}{c}\text { Technically } \\
\text { Feasible }\end{array}$ \\
\hline NPV & 1 & 3 & 1 & 4 & 3,700 & 68,000 & yes \\
\hline IRR & 2 & 1 & 3 & 4 & 3,800 & 41,000 & no \\
\hline PVR & 1 & 3 & 1 & 4 & 3,700 & 68,000 & yes \\
\hline ROIC & 3 & 4 & 2 & 1 & 3,600 & 200,000 & yes \\
\hline
\end{tabular}

When mining rate is added to the comparison, the two similar peaks are found for NPV, where a larger $\left(127,600 \mathrm{~m}^{2}\right)$ footprint is recommended, despite having $20 \%$ more capital spend, and only a 3\% increase in NPV. The results for the IRR and PVR remain similar, and the ROIC term mines at a lower rate and bigger footprint to minimise the overall NPV. By maximising ROIC though, the relative NPV, IRR and PVR are all no less than the base case of the sub level cave.

Table 3 Comparison of optimal point for variable mining rate

\begin{tabular}{|c|c|c|c|c|c|c|c|c|}
\hline $\begin{array}{c}\text { Optimised } \\
\text { Metric }\end{array}$ & NPV & IRR & PVR & ROIC & Rate & $\begin{array}{c}\text { Elevation } \\
(\mathbf{m})\end{array}$ & $\begin{array}{c}\text { Footprint } \\
\left.\text { Size } \mathbf{( m}^{\mathbf{2}}\right)\end{array}$ & $\begin{array}{c}\text { Technically } \\
\text { Feasible }\end{array}$ \\
\hline NPV & 1 & 3 & 1 & 4 & 12 & 3,700 & 127,600 & yes \\
\hline IRR & 3 & 1 & 2 & 4 & 12 & 3,720 & 41,000 & no \\
\hline PVR & 1 & 3 & 1 & 4 & 12 & 3,700 & 68,000 & yes \\
\hline ROIC & 2 & 4 & 3 & 1 & 8 & 3,580 & 140,000 & yes \\
\hline
\end{tabular}

\subsection{Proposed financial metric priority}

Depending on the operation and organisation, providing a ranking of importance of financial metrics is recommended, as opposed to a simple statement of maximising everything, which is not possible. The suggested priority list when comparing different financial investments is:

1. Present Value Ratio (PVR)

2. Net Present Value (NPV)

3. Internal Rate of Return (IRR)

4. Return on Invested Capital (ROIC)

\section{Conclusion}

Hill of Value optimisation is an important tool when understanding the financial returns of the project and enables communication of the different financial metrics required within the organisation, as well as improving the discounted cashflows and shareholder returns. A simple tool can be developed to do this analysis that takes into account a number of capital costs, and also takes into account the sub level cave above the planned block cave. This analysis agrees with the original work of Hall (2017), showing that the best financial returns for discounted financial analysis will always be above the marginal cut off of the project. Of all the financial metrics, Carrapateena has found the use of PVR more useful as it tends to focus on the efficiency of all capital spent. 
Strategic models such as this, based on a brute force optimisation technique, are useful for describing mine plans, as they allow the mine design to be based on the best strategy for the organisation, before the detailed work is done on the mine, mill and materials handling design.

\section{$5 \quad$ Acknowledgements}

The authors would like to thank OZ minerals for allowing us to publish this work.

\section{References}

Corporate financial Institute website, https://corporatefinanceinstitute.com/resources/knowledge/valuation/net-present-valuenpv/, accessed 8 March 2020.

Diering T, Richter O \& Villa D 2010, Block Cave Production Scheduling Using PCBC, SME annual meeting, Phoenix, Preprint, pp. 10-97.

Laubscher DA 2000, Practical Manual for Block Caving, Published for the International Caving Study 1997-2000.

Laubscher DA 1994, Cave mining the state of the art, Journal of South African Institute of Mining and Metallurgy, 1994, vol. 94, no. 10, pp 279-293.

Hall 2017, Cut of grade and optimizing the strategic mine plan, AUSIMM Monograph.

Hall A \& Hall B 2015, The role of Mine Planning in High performance, AUSIMM Bulletin https://www.ausimmbulletin.com/ feature/the-role-of-mine-planning-in-high-performance/, accessed 31 July 2020.

Hall B 2012, Optimising the Mining Strategy: Getting the Big Picture Value Driving Decisions right, IN: Workshop on Mass Mining Design and Planning, Sustainable Minerals Institute, Brisbane Queensland.

Hall B 2003, How Mining Companies Improve the Share Price by Destroying Shareholder Value OR How the Junior Geologist and Engineer Determine the CEO's Bonus, CIM Mining Conference and Exhibition, Montreal 2003 - Paper 1194.

Hocking R, Balog G, Omerod T \& Pearce H 2018, Early Cave Management at Carrapateena SLC, Caving 2018, Vancouver Canada

Masters S \& Hocking R 2019, Carrapateena 2019 Mineral Resources and Ore Reserves Statement and Explanatory Notes As at 30 June 2019, https://www.ozminerals.com/uploads/media/OZL_Carrapateena_MROR.pdf.

OZ Minerals 2017, OZ Minerals Carrapateena Feasibility Study Update https://www.ozminerals.com/uploads/media/170824_ ASX_Release_Carrapateena_Feasibility_Study_Update.pdf accessed 31 July 2020.

Stewart C \& Butcher RJ 2016, Block Cave Evaluation, in Proceedings Seventh International Conference and Exhibition on Mass Mining, AUSIMM: Melbourne), Sydney, pp. 809-816.

Vera M, Ovalle A \& Castro R 2019, A New Methodology Based on Hill of Value for Ore Reserve Selection in Long Term Planning for Block Caving. Mining, Metallurgy and Exploration, vol. 37, pp. 187-196. 
MINE SUPPORT SYSTEMS 